\title{
The Case of Competency and Informed Consent
}

\section{Edwin Etieyibo*}

Department of Philosophy, School of Social Sciences, University of the Witwatersrand, South Africa

\begin{abstract}
Patient competence is an essential element of every doctor-patient relationship. In this paper I provide a case report involving an older Korean man in a Hawaiian hospital who refused treatment on the basis of mistaken facts or beliefs about his doctors and treatment. I discuss the case as it relates to competency and extends it to informed consent, autonomy and paternalism. I suggest and argue firstly, that the older Korean man is not fully competent, and secondly, that if he is not fully competent, then soft and weak paternalism may be justified in his case and in cases similar to his.
\end{abstract}

\section{Introduction}

Competency is conceptually linked to informed consent and autonomy. It concerns the capacity of a person to act on his/her own behalf; consequently the evaluation of patient competence is an essential element of every doctor-patient relationship. Not surprising then that one of the most troublesome issues facing doctors is the management of medical treatment when an individual's rational decision-making ability is doubtful. In this paper I focus on a case report involving anolder Korean man in a Hawaiian hospitalwho refused treatment on the basis of mistaken facts or beliefs about his doctors and treatment. This case was first reported by Kenneth Kipnis and discussed in "Quality Care and the Wounds of Diversity"1. My aim in this paper is to discuss the case as it relates to competency. I intend extending my discussion to the context of informed consent, autonomy and paternalism and to suggest firstly, that it could be argued that the older Korean man is not fully competent, and secondly, that if he is not fully competent, then soft and weak paternalism may be justified in his case and in cases similar to his. The upshot of this is that when providing care for the patient we need not always construe paternalism and informed consent as opposed although prima facie paternalism may seem to subvert informed consent.

\section{The Case}

The older Korean man (whom we shall call Bruce) was admitted to a Hawaiian hospital. Bruce had a medical condition that was hard to diagnose and treat by the doctors. He had steadily gotten worse notwithstanding the spirited efforts of the medical and nursing staff. Eventually, the doctors thought they knew what was wrong. They followed the process of informed consent and discussed with Bruce, offering him a treatment plan that had more than $50 \%$ chance of recovery and with minimal risks. Bruce refused treatment on the ground that having suffered already, he did not want the doctors to do anything else. The decision baffled the doctors. But been assured that Bruce is competent and having followed the process of informed consent the hospital staff properly charted Bruce's refusal and awaited the excepted terminal trajectory. During the waiting period Bruce was asked the hospital's routine questions about code status. He firmly gave full support. There was a discrepancy here. Alarmed, the medical and nursing staff called for an ethics consultant that brought in Kenneth Kipnis and a hospital ethics consultant, an experience nurse. The discrepancy is between Bruce's informed refusal of potentially lifesaving treatment and his firm request for cardio version if he went into arrest. The pertinent and mindboggling question is why is Bruce rejecting a promising treatment but requesting the code which is

1. InJohanna Fisher (ed.) (2009),Biomedical Ethics: A Canadian Focus, Oxford, Oxford University Press, pp.44-47 a burdensome procedure that could prolong his life for only a brief interval? The task for Kipnis and the nurse-ethicist is to figure out what is going on and to help unpack the source of the discrepancy. Both Kipnis and the nurse-ethicist talked with Bruce at length and eventually got him to come up with a response that explained his behavior. He was worried that the doctors that were treating him were Japanese. Given that he is Korean and considering how imperial Japan ruthlessly tyrannized Korea during the first half of the twentieth century he thought that the Japanese doctors were out to get him. So what others were seeing as failures to improve his condition, he saw as successful attempts to cause his death. "Paradoxically, he was refusing life-saving treatment in order to save his life." Kipnis and the nurseethicist reported their findings to the hospital and they agreed with their recommendation. Within a few hours they got a non-Japanese doctor to persuade him to accept treatment.

\section{Discussion of the Case}

If the ethics consultant had not been called in Bruce would have died? This raises an important question: Was Bruce competent in this case to reject or accept treatment? On the surface it would seem that he is competent. When the doctors explained the intervention to Bruce he seems to have understood and appreciated his options and the consequences of his choice. But I want to suggest that Bruce was not fully competent. His lack of competency I will argue results from the fact that he has mistaken beliefs about the doctors and the planed intervention, namely that the Japanese doctors wanted to kill him and the treatment was designed to do exactly that. These mistaken beliefs skewed his ability to properly and rationally engage with his options in the right sort of way. If this is right, then I suggest that soft and weak paternalism are legitimate and justified in cases were a patient has mistaken beliefs about her medical situation(namely, medical condition, the natural course of the medical condition, the proposed treatment intervention, the risks and potential benefits, the consequences of treatment or intervention refusal, viable alternatives) insofar as such beliefs affect and skew his/her ability to properly and rationally engage with his/her options in the right sort of way.

*Corresponding author: Edwin Etieyibo, Department of Philosophy, School of Social Sciences, University of Witwatersrand, E-mail: edwin.etieyibo@wits.ac.za

Received March 21, 2013; Accepted April 29, 2013; Published May 04, 2013

Citation: Etieyibo E (2013) The Case of Competency and Informed Consent. J Clinic Res Bioeth S12: 001. doi:10.4172/2155-9627.S12-001

Copyright: (c) 2013 Etieyibo E. This is an open-access article distributed under the terms of the Creative Commons Attribution License, which permits unrestricted use, distribution, and reproduction in any medium, provided the original author and source are credited. 


\section{Competency}

Competency is a legal term which refers to the capacity of a person to act on his/her own behalf. Within the medical profession and as it relates to a patient it is broadly construed as the ability of a patient to understand the information that he/she is presented, to appreciate the consequences of acting or not acting on that information, and to make a choice on the basis of such information. ${ }^{2}$ Simply put, competency is about understanding and choice; understanding the medical condition, the natural course of the medical condition, the proposed treatment intervention, the risks and potential benefits, the consequences of treatment or intervention refusal, viable alternatives and choosing according to one's understanding. ${ }^{3}$ One consequence of this take on competency is that there shouldn't be any discrepancy between the patient understanding of the information, her preference and choice. A quick example will be a patient that consents to surgery but refuses anaesthesia. In current medical practice, it is considered that patients who have consented to surgery have given their implied consent to anaesthesia, despite the fact that anaesthesia carries its own particular set of risks and consequences that are independent of the risks and consequences associated with surgery. ${ }^{4}$ Thus it would appear contradictory for a patient to consent to surgery and then to refuse anaesthesia. To understand patient competence this way is to link competency to informed consent and autonomy since valid informed consent requires that the patient be competent to make medical decisions. Given this connection and if we are to understand competency it will be helpful to first of all understand informed consent and autonomy. ${ }^{5}$

\section{Informed Consent and Autonomy}

Informed consent simply means that the consent of a patient to any intervention has to be informed. The idea of informed consent is grounded on the more fundamental notion of autonomy, a term that comes from the Greek auto (which is self) and nomos (which means rule), where aautonomy means the right of a rational, mentally mature individual to make decisions regarding his/her own life. Being grounded on autonomy means that informed consent can be seen as process, a process of information sharing with the aim of involving the patient in making decisions in matters relating to his or her health. ${ }^{6}$ Being informed in this context therefore, implies cognition, willingness, consideration, intention and understanding. That is, a "patient should be able to comprehend the meaning of the information, balance pros and cons, draw inferences from the data with reasonable rationality, assess the circumstances, appreciate the aspects of the situation, and reach a deliberate decision on the basis of the available information." ${ }^{7}$ Simply put then, informed consent can be seen one the one hand, as the process by which a fully competent (rational, mentally mature) patient or subject participates in choices about his or her healthcare and, on the other, as placing a legal and ethical duty on healthcare professionals regarding the care of patients. If the duty that is placed on healthcare professionals is one that obligates them to involve patients in decision involving their medical careit is important then that the information that such patients are provided with be communicated in a manner that is consistent with their capacities to understand the information as well as in a form that maximizes such understanding.

\section{Bruce and Competency}

Was Bruce competent? I want to argue that he is not, or at least not fully competent even though he seems to understand the information about his medical situation that he is given by the doctors and makes his choice on the basis of this. The silent idea about competency is that the patient's choice is a reflection of his understanding of the information provided considered along with his preference. In other words, his choice reveals his understanding and preference. This means that one informal way of assessing whether or not a patient is competent is whether or not his choice conflicts with his understanding of the information and the particular preference that he holds. So to give a trivial example. Suppose that you know that I prefer to live. Suppose also that I am walking down a bridge that is in bad condition and I don't know about the condition of the bridge. ${ }^{8}$ Suppose that you communicate to me that the bridge is falling and that if I walk on it I will fall down. Suppose finally that I indicate to you that I understand what you just communicated to me. If we take together my understanding of what has been communicated to me and my preference, then I would be expected not to walk on the bridge. If however, I choose to walk on the bridge, then it could be concluded that my choice is in conflict with my understanding and preference, which may legitimately raise the question about my competence.

That seems to be what was happening in the case of Bruce. Although he appears to understand when the doctors explained the intervention to him, his options and the consequences of his choice, his choice nevertheless is in conflict with his understanding and preference. It is this conflict revealed in the discrepancy that led to the invitation of the ethics consultant. The discrepancy is that Bruce firmly accepted a cardio version but rejected a potentially life-saving treatment. This discrepancy although picked up by the medical and nursing staff was only unpacked following the lengthy discussion that Kipnis and the

2. For some interesting discussions of the concept of competence see J.V Welie and S.PWelie (2001) "Patient Decision Making Competence: Outlines of a Conceptual Analysis", Medical Health Care Philos 127-138; J. Leo Raphael (1999) "Competency and the Capacity to Make Treatment Decisions: A Primer for Primary Care Physicians". Primary Care Companion Journal of Clinical Psychiatry 1: 131-141.

3. Jean Kutner et. al., states it similarly by dividing competency into five categories: (1) expressing a choice;(2) choice with a "reasonable" outcome (3) choice based on "rational" reasons; (4) ability to understand; and (5) appreciation of the situation and its consequences, Jean S. Kutner, John.E Ruark, Thomas A. Raffin (1991)“Defining Patient Competence for Medical Decision Making". Chest 100:1404-1409.

4. Although White has argued that since anaesthetists often perform interventions that are the only medical treatment received by a patient, they should always obtain separate consent for anaesthesia, S. M. White (2004) "Consent for anaesthesia". Journal of Medical Ethics 30: 286-290.

5. The need to unpack the concept of informed consent and to develop it further may be poignant and relevant when one considers the result of the study of informed consent prior to nursing care procedures by qualified nurses in two teaching hospitals in England. The study shows that consent was often "not obtained by those who participated in the study and that refusals of care were oftenignored. In addition, participants were often uncertain how to proceed with care when the patient was unable to consent", Helen Aveyard (2005) "Informed Consent Prior to Nursing Care Procedures". Nursing Ethics 12:19-29.

6. My treatment of the relationship between informed consent and autonomy follows the practice in the medical profession and bioethics where the requirement of informed consent to medical treatments is justified with appea to patient autonomy even though Kihlbom has argued that the conceptual link between informed consent and autonomy is much weaker than conventionally conceived. See U. Kihlbom (2008) "Autonomy and Negatively Informed Consent". Journal of Medical Ethics 34: 146-149.See alsoT. Beauchamp and J. Childress, Principles of Biomedical Ethics, 3rd edition, Oxford: Oxford University Press, 1989.

7. Israel National Commission for UNESCO, "Informed Consent", p.11

8. This example is famously attributed to John Stuart Mill. 
nurse-ethicist had with Bruce. As Kipnis rightly points out, the case clearly highlights the significance of ethics consultation to patient care, and the importance of understanding the patient's underlying cultural differences and value commitments.

Kipnis'sobservation about what is highlighted by the case fits in with the individual therapy stage or model of informed consent, which emphasizes the importance of recognizing the relevant psychological characteristics of patients. ${ }^{9}$ Since competency is situated within understanding and choice, factors thatmay undermine a patient's competency to consent are generally understood in terms of whether they diminish a patient's ability to understand, evaluate and decide. Some of the things that may undermine competency range from ppsychological and physical factors to social, cultural, financial, and cognitive factors. Ppsychological and physical factorsrelate to illness, the presence of pain and medication, fear, anxiety, guilt, depression; social and cultural factors, such as ssocial and family responsibilities, and cultural expectations about values and behavior; financial factor concerns affordability of treatment and intervention; cognitive factor, namely, the lack of information relating to decision, inadequate understanding of information regarding complex medical situations. All of these factors can compromise competency simply by impairing an individual's usual ability to think and act in a responsible manner.

My argument that Bruce is not fully competence simply is an argument that his ability to make an informed choice is impeded cognitively (or broadly put, limited by a set of cognitive factor). On the common understanding of competence, cognitive factor undermines patient competence when minimally either (C1) a patient does not have adequate information regarding her medical situation or (C2) she has an inadequate understanding of the information about her medical situation. Thus to reach the conclusion that Bruce is not competent and that his lack of full competence is cognitively limited I need to show that his case of mistaken beliefs is either of $\mathrm{C} 1$ or $\mathrm{C} 2$. I suggest the Bruce mistaken beliefs are of C2insofar as the mistaken beliefs undermine his ability to choose properly and to act in a responsible manner. If I believe that humans can float and therefore conclude that it is best that you and I or humans in general should be jumping off high places as a means of transporting ourselves from one location to another, then clearly it is reasonable to conclude that I am not competent to make decision about the best way of transporting humans. My lack of competence here simply arises from consideration about my mistaken belief about humans and what they can do. Similarly, it can be concluded that Bruce's mistaken beliefs render him not fully competent with regards to his medical situation.

If I am right about this then the case of Bruce not only highlights all the right things that Kipnis said above but also that paternalism may be justified in cases where the patient has mistaken beliefs about his medical situation. Stated otherwise, that soft and weak paternalism may be justified in cases where the patient is not truly acquainted with facts that are important for him to understand his medical situation notwithstanding the fact that prima facie paternalism seems to subvert informed consent. I now turn to the argument in support of this claim.

\section{Paternalism}

Paternalism refers to a class of actions by a person, organization or state that limit some person or group's liberty or autonomy. Or broadly, it refers to the interference of a state or an individual with another person, against his or her will. Such interference or limitation of autonomy is generally motivated by the welfare of those whose autonomy is interfered with, that is the claim that such interference makes them better off or protected from harm. Class of actions that are paternalistic is pretty ubiquitous. These actions are performed by the state, various institutions and individuals. Examples of some of those performed by the state include the government requiring people to contribute to a pension system, wearing seat belts (or motorcyclists wearing helmets), minors to have blood transfusions even if their religious beliefs forbid it, prohibiting people from swimming at a public beach when lifeguards are not present, banning the sale of various drugs deemed to be ineffective and those believed to be harmful. Those actions performed by institutions and individuals include partial or non-disclosure to patients the truth about their medical condition, invitations that directly encourage participation of women in mammography screening, ${ }^{10}$ a husband hiding sleeping pills from a depressed wife, a teacher been less than forthright about telling a student that she has little analytical and philosophical ability, a friend telling another friend that she doesn't look fat in the dress whereas in fact she does.

There are different forms of paternalism. There is soft and hard paternalism. The former is the view that paternalism is justified if the person being interfered with is not acting voluntarily or knowledgeably, and the latter is the view that paternalism is sometimes justified even in cases where the person being interfered with is acting voluntarily or knowledgeably. We can illustrate the difference between both with the bridge example. Suppose that as in above I am about to walk across a damaged bridge. Suppose also that you are not able to communicate the danger to me. Soft paternalism would say that it is justifiable to forcibly prevent me from crossing the bridge in order to determine whether I genuinely know about its damaged condition. But suppose that you are able to communicate the condition of the bridge to me and I know this, but want to, say, commit suicide. Soft paternalism would say that I must be allowed to proceed according to my preference as interfering with me would completely violate my liberty and autonomy. Hard paternalism, on the other hand, would say that insofar as we ought to prevent voluntary suicide it is at least sometimes permissible to stop me from crossing the bridge even if I am aware of its damage condition and want to commit suicide.

There is also weak and strong paternalism. The difference between both is simply a difference about whether we are justified to interfere with people's choices in situations where they are mistaken about facts and values. Weak paternalism holds that we may interfere only when people are mistaken about facts and strong paternalism holds that we may interfere when they are mistaken either about facts or values. In order words, weak paternalism claims that interfering with the means that people choose to achieve their ends is justified, insofar as those means are likely to defeat those ends. An example would be a person that truly prefers safety to convenience. Weak paternalism would say that it is legitimate to force such a person to wear seatbelts. Strong paternalism claims that because people may be mistaken or confused about their ends it is justified to interfere with such means in order to prevent them from achieving those ends. So if a person genuinely prefers the wind swirling through their hair to increased safety strong

9. For a discussion of this stage and the three other stages of informed consent see Bruce N. Waller and Robyn A. Repko (2008) "Informed Consent: Good Medicine, Dangerous Side Effects". Cambridge Quarterly of Healthcare Ethics 17: $66-74$.

10. K J Jørgensen, J Brodersen, O J Hartling, M Nielsen, P C Gøtzsche (2009) "Informed Choice Requires Information About Both Benefits and Harms", Journal of Medical Ethics 35: 268-269 
paternalism would say that it is justified to make them wear helmets while on a motorcycle since their ends are irrational or mistaken. ${ }^{11}$

\section{Bruce and Paternalism}

So because broadly, paternalism does seem to interfere with the liberty or autonomy of an individual, doing so to improve that person's welfare albeit without his or her consent it is clear that at some level it is opposed to informed consent. But as I will be arguing (using the case of Bruceas an example) that although prima facie paternalism seems to subvert informed consent we need not always construed paternalism and informed consent as opposed. Suppose that as a healthcare practitioner one is attending to a middle age man who has a 6-month history of chest pain and fainting spells. Suppose also that one feels that his symptoms merit some intervention, say, and cardiac catheterization. In line with the process of informed consent one explains to him the risks and potential benefits of the planned treatment. One also includes an assessment of probable prognosis without the intervention. $\mathrm{He}$ is able to demonstrate that he understands all of this, but refuses the intervention. What should we do? If one takes informed consent as always opposed to paternalism one may conclude that any intervention against the wish of the man would be paternalistic and consequently a violation of the process of informed consent (if as we have said informed consent involves a patient's active participation in choices about his or her healthcare). But if one understands informed consent and paternalism as not always opposed, then one may interpret slightly differently any intervention against the patient's wish. This last point is clearly highlighted in the case of Bruce.

Were the doctors to force the intervention on Bruce they would have acted consistently with soft and weak paternalism. We know this because Bruce eventually accepted the intervention, but doing so after his discussion with Kipnis and the nurse-ethicist has established that he is mistaken about certain facts (that the doctors wanted to kill him and that the intervention is a way of killing him). To draw an analogy with the bridge example Bruce like the man crossing the damage bridge (who does not know about the condition of the bridge) does not know that the doctors want to kill him and that the intervention is designed to end his life. If the man knows about the condition of the bridge, he would not walk on it given his preference to live. So too if Bruce knows the real facts about the doctors and the intervention he would not reject the intervention. He only comes to know and appreciate the real facts after the non-Japanese doctor presented him the same treatment plan that the Japanese doctors gave him. So clearly it wasn't the case that the Japanese doctors wanted to kill Bruce. It also isn't the case that the intervention was designed to kill him. But suppose that he truly knows the facts as they are but then still refuses the intervention then of course we would reach a different conclusion. We would simply say that his decision is not about the facts but about values themselves. And since I defend the claim that soft and weak paternalism may be justified sometimes but not hard and strong paternalism we may simply reject any interference in this case as legitimate.
We can parse the experience of Bruce into three episodes. Bruce 1 is Bruce before he came to the hospital; Bruce 2 is Bruce in the hospital but pre-diagnosis and intervention, and Bruce 3 is Bruce in the hospital but post-diagnosis and intervention. Bruce in all three episodes is the same person, has the same preference, namely he prefers living to dying. By preferring living to dying Bruce is like the person that truly prefers safety to convenience and who is to forced to wear seat belts. Bruce' preference throws up the discrepancy that the medical and nursing staff picked up and that motivated the invitation of Kipnis and the nurse-ethicist. Now, since Bruce is the same in Bruce 1-Bruce 3, or better put his preference is consistent in all three Bruce episodes it makes no significant moral difference whether the intervention was done prior to the heavy lifting of Bruce cognitive state by Kipnis and the nurse-ethicist or afterwards for in either case the intervention preserves intact the preference of Bruce in Bruce 1, Bruce 2 and Bruce 3. Or put differently, an intervention done without the benefit of an ethics consultation unpacking Bruce's cognitive state or one done with the benefit of an ethics consultation unpacking Bruce's cognitive state is the same, morally speaking. They both, from the moral point of view, similar in that they are consistent with Bruce's considered coherent preference (to live). Of course, if Kipnis and the nurse-ethicist have not come into the picture, and if the medical and nursing staff had gone ahead with the intervention, the temptation is to say that they have violated Bruce's autonomy and consequently subverted informed consent. But this would be misguided, since we have established that Bruce' mistaken beliefs render him not fully competent and thus subject to some kind of paternalistic treatment and actions, particularly those actions that are consistent with his preference.

\section{Conclusion}

Although my case report focuses on Bruce, my discussion of the report is meant to help tease out not just the importance of understanding the patient's underlying cultural and value commitments but also the justification for soft and weak paternalism. From the discussion three points have been established. Firstly, those facts are often intertwined with values and that in living up to the demand of informed consent and autonomy it is important that we separate both. Secondly, that Bruce is not fully competent about his medical situation. Thirdly, that soft and weak paternalism may be broadly justified in cases where the patient is not fully competent, namely, where she has mistaken beliefs that seem to undermine her ability to comprehend the meaning of the information and able to balance pros and cons, draw inferences from the data with reasonable rationality, and reach a deliberate decision on the basis of the available information. My argument for and defence of soft and weak paternalism seems consistent firstly with the individual therapy stage or model of informed consent which emphasizes the importance of recognizing the relevant psychological characteristics of patients, and secondly, with established positions in the medical practice and in bioethics about competency and various factors that may undermine competence.
11. For further discussion of the differences between these types of paternalism and others and their justification see "Paternalism",Stanford Encyclopedia of Philosophy. Accessed March 9, 2013. Much of my discussion of the different types of paternalism and some of the examples are from this article.
This article was originally published in a special issue, Case Reports in Bioethics handled by Editor. Azetsop J, Department of Medical Ethics, South Africa 